\section{THE MENTAL FUNCTIONS OF THE BRAIN.}

Th the Editors of THE LANCET.

SIRs, - I have to thank you for the review of my book on "The Mental Functions of the Brain," which appeared in The LaNCET of Oct. 19th, p. 1051. If, as your reviewer says: "The work is a pretentious one and its claims are of an exceptional character," it seems to me a pity that he should have ignored one-third of it, containing some important statements, which-if they are not true-require immediate contradiction. It is stated in the book:

1. That there is not one man of scientific repute who has written anything which would indicate that he has examined 'Gall's chief work on the Anatomy and Physiology of the Nervous System. 2. That Gall's discoveries, anatomical and physiological, particularly the former, were ignored even by his most scientific followers, so that the world is ignorant of them. 3. That any one of the numerous anatomical discoveries, presented for the first time in this book, should have sufficed to bring Gall fame, but that there is not one text-book in the United Kingdom dealing with the anatomy of the brain which even mentions his name. 4. That his localisation theory has been misrepresented throughout the past century and most actively by those who found the principles of his doctrine useful but wished to hide the fact to escape the popular bias against phrenology. 5. That as a consequence of this foolish opposition for a whole century we still disagree even as regards such a fundainental localisation as that of the intellect. One school considers the frontal lobes to be the seat of the higher intellectual operations, another the occipital lobe, Rüdinger the upper part of the parietal lobe, Professor Cunningham ${ }^{1}$ the lower part of the parietal lobe. Whereas Gall has collected for many of his investigations clinical, pathological, and experimental evidence, some of the recent observers advocate the method of looking for "protuberances." 6. There are many other important statements in the book. To give one more example, Gall has described the first genuine case of "aphasia" (see p. 230), yet we still give Broca the chief credit, and those who acknowledge Gall often speak of his discovery as a "mere happy guess."

By ignoring this part of the book your reviewer makes it appear as if I were reviving the phrenology of the self-styled "professor," and thus, unintentionally, excites the prejudices of the readers of his review against the book.

Now as to the "several" post-mortem records which I am supposed to quote in support of the theory that the lesion in irascible insanity and violent mania is to be found in the temporal lobe. My "several" records number 350, the majority of them being injuries to the temporal area, localised tumours, and circumscribed inflammatory disorder. The minority are cases in which a lesion took place in some adjoining part, but involved the temporal lobe by extension. Your reviewer selected one of the latter cases as a "typical instance of my method of stating facts and deducing conclusions." Unfortunately this is one of the three cases (out of 800) which got into the book by some error and was marked by me for "revision" or "omission" for the second edition. I acknowledge my responsibility, but to describe this case as typical of the 350 quoted in favour of the localisation of irascible insanity is clearly a misrepresentation. I have had to quote my cases as I found them in the clinical records, foreign cases having been translated and the British cases left unaltered except for the condensation where necessary, so that in most cases the authors themselves are responsible for their records.

However opinions may vary as to the value of the deduotions at which I have arrived your reviewer is the first not to acknowledge the vast amount of material which I have collected in this book for the benefit of future investigators; and considering the absence of positive knowledge as regards the mental functions of the cortex, the growth of the brain, the significance of its size and weight, investigators can little afford to sneer at an honest attempt at an elucidation of these problems, such as I have made.

I am, Sirs, yours faithfully,

\section{London, Oct. 21st, 1901 BERNARD HOLLANDER, M.D.}

1 See Presidential Address, British Assooiation (Anthropologioa Section), Glasgow September, 1901.

\section{THE ETHICS OF THE PUBLIC VACCINA'TOR.}

To the Editors of THE LANCET.

SIRs,-Owing to the complaints one hears upon all sides as to the elastic manner in which some of the public vaccinators are interpreting the duties of their office I have ventured to submit to you a series of questions which are not without interest to general practitioners at the present time.

1. Should a public vaccinator who is appointed to a definite district vaccinate anyone who comes to his house, irrespectively of where they reside, or should he find out their address and refer them to the public vaccinator of that district?

2. Can a public vaccinator charge the authorities for work done by his qualified assistants to whom he pays a salary of three or four guineas a week?

3. Should a public vaccinator interview the principals of large firms where he knows there is a regular medical attendant and induce them to allow him to vaccinate their employés under the plea of gratuitous operation?

4. In the event of his vaccinating a large staff should he ascertain whether any of the members who live at home would prefer to be vaccinated by their own private medical attendants ?

5. If when making a house-to-house inspection a public vaccinator finds that certain of the inmates intend to be vaccinated by their own medical men, is he justified in persuading them to be operated upon by himself on the grounds that he will do so free of charge?

6 . Is it a professional act for a public vaccinator to attract children by means of chocolates, apples, \&c. ?

Will you kindly publish the fees which are now being paid per head to public vaccinators in the different districts of the county of London. The medical profession will have to pay their share of the vaccination rate, and this in some cases will mean paying for the vaccination of our own patients.

Nov. 4th, 1901. I am, Sirs, yours faithfully,

General Practitioner.

\section{A SANITARY OUTRAGE.}

To the Editors of $\mathrm{THE}$ LANCET.

SIRS, - Will it be believed that the Westminster City Council erected two stands for themselves and their friends in the Green Park opposite Devonshire House over the two public urinals which exist at that spot, necessitating the closing of these necessary conveniences for the whole of Friday and Saturday last? Their friends doubtless appreciated the invitation to lodge in the W.C. district and, I hope, enjoyed their visit, but I should like to know whether the Westminster Council had the right to interfere with the comfort of thousands who were thus forced to relieve the wants of nature in the neighbouring park.

I am, Sirs, yours faithfully,

Nov. 4th, $1901 . \quad$ AN OLD Privy Councthlor.

\section{NOTES FROM INDIA.}

(From our Speclal Correspondent.)

The Plague Epidemio.-Plague Administration in Bombay City.-The Famine and the Rains.-Deaths from Wild Animals. - The Victoria Scholarship Fund for Training Native Midwives.-Cocaine-eating in Bengal.

THE mortality from plague throughout India is still increasing. The outbreaks in the Belgaum and Dharwar districts of the Bombay Presidency have further developed and account for the greater number of deaths. The disease, moreover, is spreading in the Punjab and at Poona. For the latter health camps have again been opened. Since the recrudescence which commenced in August 112 cases have been reported. In the Punjab the cases have increased during the past week from 181 to 301 , and 15 deaths are reported from the province of Jummu. In Bombay city the deaths from plague are somewhat fewer, and in Calcutta the number fluctuates week by week between 12 and 20 .

A great change is in course of operation in the plague administration of Bombay city. The Commissioner still remains the head of the department, but immediate 